\title{
Adsorptive Stripping Voltammetric Determination of Trace Level Ricin in Castor Seeds Using a Boron-doped Diamond Electrode
}

\author{
Williame F. Ribeiro, ${ }^{[\mathrm{a}]}$ Daniel J. E. da Costa, ${ }^{[\mathrm{b}]}$ Anabel S. Lourenço, ${ }^{[\mathrm{b}]}$ Everaldo P. de Medeiros, ${ }^{[\mathrm{c}]}$ \\ Giancarlo R. Salazar-Banda, ${ }^{[\mathrm{d}]}$ Valberes B. do Nascimento, ${ }^{[\mathrm{e}]}$ and Mario C. U. Araujo ${ }^{[\mathrm{b}]}$
}

\begin{abstract}
Ricin, (Ricinus communis agglutinin, RCA) is one of the most poisonous of naturally occurring substances and has great potential for bioterrorism because no antidote exists. Fast detection at low concentrations is a challenge, and vital to the development of proper countermeasures. In this study, a square wave adsorptive stripping voltammetric (SWAdSV) method for determining RCA using a cathodically polarized boron-doped diamond (BDD) electrode is presented. An irreversible electrochemical RCA oxidation peak was identified on the BDD electrode by different voltammetric techniques using both direct and adsorptive stripping modes. An adsorption-controlled (slope $\log \mathrm{Ip}$ vs $\log \mathrm{v}$ of 0.80 ) $\mathrm{pH}$ dependent process was observed. For values of $1.0 \leq \mathrm{pH} \leq$ 9.0, the numbers of protons and electrons associated with the oxidation reaction were estimated (ca. 1.0) by differential pulse voltammetry. The RCA oxidation step may correspond to the oxidation of tryptophan amino acid residues, and occurs in a complex mechanism. The
\end{abstract}

excellent analytical performance of the cathodically polarized BDD electrode in combination with the stripping mode ramp was verified with RCA by using a short deposition time in an open circuit potential (120 s). Under optimized analysis conditions, a linear response in the range of $(3.3-94.0) \times 10^{-9} \mathrm{~mol} \mathrm{~L}^{-1}\left(\mathrm{r}^{2}=0.9944\right)$ and a limit of detection of $6.2 \times 10^{-10} \mathrm{~mol} \mathrm{~L}^{-1}$ were estimated. This LOD is lower than several methods found in the literature. For example, it is 168 times lower than that obtained by using square wave voltammetric with a glassy carbon electrode. Moreover, an even lower LOD might be achieved by using the SWAdSV method with a higher pre-concentration time. In addition, trace levels of RCA were successfully determined in different castor seed cultivars with an overall average recovery from $99.2 \pm$ $1.6 \%$ for the three different RCA-A concentration levels. The high accuracy of the analytical data highlights the use of the proposed method for determining RCA in other samples.

Keywords: Ricin • Castor seeds • Adsorptive stripping voltammetry • boron-doped diamond electrode

\section{Introduction}

Ricin (Ricinus communis agglutinin, RCA) is a high molecular weight $(60 \approx \mathrm{kDa})$ phytotoxic protein extracted from castor bean plant seeds that has been attracting the attention of both the scientific community (to treat terminal cancers and AIDS), and of criminals (to produce chemical weapons for warfare) [1,2]. RCA is classified as one of the most toxic biological warfare or bio-terror agents to which people could be exposed, by air, food or water [3].

RCA is a complex molecule with two polypeptide chains: A-chain (RCA-A, cytotoxic, $\approx 30 \mathrm{kDa}, 267$ essential amino acid residues), and B-chain (RCA-B, galactose-lectin, $\approx 30 \mathrm{kDa}, 262$ essential amino acid residues), united covalently by a single disulfide bond [2] The B-chain is essential for cell surface binding and transports the A-chain into the cytosol. The A-chain is toxic to cells, stopping protein production and leading to cell death [4].

RCA toxicity, discovered by Stillmark in 1888 [1], is due to its catalytic action on eukaryotic ribosomes. Included as a restricted substance in Schedule I of the
Chemical Weapons Convention, RCA is dangerous to insects, animals and humans. In humans, clinical manifes-

\section{[a] W. F. Ribeiro}

Universidade Federal da Paraíba, Centro de Ciências Aplicadas e Educação, Departamento de Engenharia e Meio Ambiente, 58297-000, Rio Tinto, Paraíba, Brasil

[b] D. J. E. da Costa, A. S. Lourenço, M. C. U. Araujo

Universidade Federal da Paraíba, Departamento de Química, Laboratório de Automação e Instrumentação em Química Analítica/Quimiometria, Caixa Postal 5093, 58051-970, João Pessoa, Paraíba, Brasil

E-mail: mariougulino@gmail.com

[c] E. P. de Medeiros

Empresa Brasileira de Pesquisa Agropecuária - EMBRAPA Algodão, 58107-720, Campina Grande, Paraíba, Brasil

[d] G. R. Salazar-Banda

Universidade Tiradentes, Laboratório de Eletroquímica e Nanotecnologia, Instituto de Tecnologia e Pesquisa, Programa de Pós-graduação em Engenharia de Processos, 49032-490, Aracajú, Sergipe, Brasil

[e] V. B. do Nascimento

Universidade Federal Rural de Pernambuco, Departamento de Química, 52171-900, Recife, Pernambuco, Brasil 
tations depend on the route of exposure; such as inhalation (respiratory distress, fever, and cough followed by the development of pulmonary edema, hypotension, respiratory failure, and possibly death within 36 to 72 hours), ingestion (profuse vomiting and diarrhea, followed by multi-system organ failure and possibly death within 36 to 72 hours of exposure), or injection (which produces severe internal bleeding and tissue death, and can result in the collapse of major organ systems) $[5,6]$. Consider the acute toxicity of RCA in mice [7,8]; approximated values for lethal dosage (LD50) and average time till death are established for inhalation, ingestion, and subcutaneous injection, respectively at $3-5 \mu \mathrm{g} \mathrm{kg}^{-1}(60 \mathrm{~h}), 20 \mathrm{mg} \mathrm{kg}^{-1}$ (85 h), and $24 \mu \mathrm{g} \mathrm{kg}^{-1}$ (100 h).

Regarding its extremely toxic nature, many attacks using RCA have been reported, such as: the assassination of the Bulgarian journalist Georgi Markov (London, 1978); a vial containing the toxin was found at a post office in Greenville (South Carolina, 2003); RCA was found in the mailroom of three US Senate office buildings which were temporarily closed (Washington, 2004), and, recently, RCA was found in letters sent to President Barack Obama and a Mississippi Senator (USA, 2013) [7].

Detection of RCA in contaminated samples, including body tissues and many other materials, as well as food, milk, and tap water has followed several lines of investigation. Recently, various methods, such as electrophoretic and chromatographic separations, fluorescence, biosensors and immunochemical assays, and especially screening analysis (ELISA - Enzyme Linked Immunosorbent Assay), were reviewed by Musshoff and Madea [4]. Nevertheless, these methods are laborious, expensive, require biochemical tests and sophisticated equipment with highly skilled workers and include several steps. Thus, considering the importance of RCA trace-analysis, development of new analytical methods in this area is of substantial importance.

Due to simple instrumentation, inexpensive equipment, low operating costs, high selectivity and sensitivity, better reproducibility, broad linear dynamic range and easy sample preparation, our group recently reported on a proposed voltammetric method for determination of RCA and its electrochemical behavior using different voltammetric techniques on a glassy carbon (GC) electrode [9]. The square wave voltammetry (SWV) method developed presented a good linear relationship between peak current and concentration (from $4.0 \times 10^{-7}$ to $2.0 \times 10^{-6} \mathrm{~mol} \mathrm{~L}^{-1}$ ), and a limit of detection (LOD) of $5.3 \times 10^{-8} \mathrm{~mol} \mathrm{~L}^{-1}(3.2$ ppm). However, the structural complexity of RCA and its strong adsorption on the GC electrode surface required electrode surface cleanings between each voltammetric measurement, impairing the reproducibility, accuracy and the analysis time. To overcome these drawbacks, the use of a boron-doped diamond (BDD) electrode was reported as a good alternative when compared to conventional working electrodes (e.g. GC, carbon paste, gold, platinum, and mercury electrodes) due to it exhibits superior electrochemical properties, such as: chemical stability, a large potential window, low and stable background current over a wide potential range, high thermal conductivity and resistance to electrode fouling [10-12].

In the last thirty years, BDD has been widely investigated in electroanalysis, especially for voltammetric determination, preferably using cyclic voltammetry (CV), differential pulse voltammetry (DPV) and/or SWV (direct and stripping modes) for both organic and inorganic substances in real samples in trace levels [11-15]. BDD electrodes are well-faceted, hydrophobic, and have low surface energy, so they are a viable material for the direct oxidation of proteins [16]. These proteins can vary from synthetic oligonucleotides and nucleosides (guanosine and adenosine) [17], myoglobin and hemoglobin [18], cytochrome c [19], tyrosine derivatives and protein tyrosine kinase [16], DNA nucleotides [20], peptide methionine sulfoxide reductase [21], and among other constituents, RCA amino acids [21-23].

The anodic or cathodic pretreatments of BDD electrodes have a significant effect on the voltammetric response for systems. Suffredini et al. [24] investigated the effect of these pre-treatments on BDD using well-known reversible systems (solutions containing either $\mathrm{K}_{4} \mathrm{Fe}(\mathrm{CN})_{6}$ or ferrocene in aqueous $0.5 \mathrm{~mol} \mathrm{~L} \mathrm{~L}^{-1} \mathrm{H}_{2} \mathrm{SO}_{4}$ ), showing that for both electrochemistry systems quasi-reversible peaks were observed after anodic pretreatment, and reversible peaks after cathodic pretreatment. These observations were confirmed using electrochemical impedance spectroscopy measurements of the DDB electrodes, pre-treated with both types of polarization. According to the authors, a cathodic surface polarisation of the electrode prior to measurements leads to an enhanced electrochemical activity.

In this paper a more sensitive, reproducible and accurate square wave adsorptive stripping voltammetric (SWAdSV) method for the determination of trace RCA is presented, using a cathodically polarized BDD electrode. The sensitivity of the proposed SWAdSV method is increased when compared to our previous method [9] due to the use of the adsorptive stripping voltammetric (AdSV) technique.

AdSV stands out as an efficient technique to assay trace concentrations of several species that adsorb onto working electrode surfaces [25], including BDD electrodes $[12,26]$. AdSV technique involved pre-concentration of RCA on the electrode surface, followed by a potential sweep that strips material from the electrode surface off and back into solution. During this last step a voltammogram is recorded and used to obtain the RCA concentration in the sample.

In order to compare the results between the BBD and GC electrodes, preconcentration studies of RCA were also performed on the open circuit GC electrode. However, a drastic current loss was observed when compared to the voltammetric response with no deposition time. Therefore, the determination of RCA was not possible by AdSV using CG electrode. 


\section{Experimental}

\subsection{Apparatus and Reagents}

In potentiostatic mode, an Eco Chemie, $\mu$ Autolab $^{\circledR}$ Type II, potentiostat coupled to a module was used for all voltammetric experiments. A three-electrode electrochemical cell was used with platinum wire, $\mathrm{Ag} / \mathrm{AgCl}$ (3 mol L $\left.{ }^{-1}, \mathrm{KCl}\right)$, and BDD, (BDD plates $(1.2 \mathrm{~cm} \times 1.2 \mathrm{~cm})$ with a geometric surface area of $0.36 \mathrm{~cm}^{2}$; an $8000 \mathrm{ppm}$ boron film was prepared in the Centre Suisse d'Electronique et de Microtechnique SA (CSEM), Neuchâtel, Switzerland [27]) and employed as counter, reference and working electrodes, respectively. A GC electrode ( $\mathrm{mm}$, diameter) was used for comparison, and as working electrodes for RCA detection.

All other chemicals were of analytical grade. The solutions and subsequent dilutions were prepared daily with ultrapure water purified using a Millipore Milli-Q System (conductivity $\leq 0.1 \mu \mathrm{S} \mathrm{cm}^{-1}$ ).

Buffer solutions $\left(0.1 \mathrm{~mol} \mathrm{~L}^{-1}\right)$ were prepared and employed as supporting electrolytes following the procedure described by Oliveira et al. [28]: $\mathrm{HAc} / \mathrm{NaAc}(\mathrm{pH} 3.6$ and 5.4); $\mathrm{NaH}_{2} \mathrm{PO}_{4} / \mathrm{Na}_{2} \mathrm{HPO}_{4}$ (7.0) and Borax $/ \mathrm{NaOH}(\mathrm{pH}$ 9.0). In addition, a $0.1 \mathrm{~mol} \mathrm{~L}^{-1}$ sulfuric acid solution $(\mathrm{pH}$ 1.0) was also used.

As a pure RCA model, ricin A-chain (RCA-A) from Ricinus communis (castor bean), purchased from SigmaAldrich, was used. Stock solutions of RCA-A $\left(1.0 \times 10^{-3}\right.$ mol $\mathrm{L}^{-1}$ ) were prepared in water and stored under refrigeration.

Due to the high toxicity of the RCA, severe safety measures were adopted during its handling, as the use of gloyes, goggles, safety mask and chemical fume hood.

\subsection{Electrode Preparation and Measurement Procedure}

Using carefully the procedures previously described by Salazar-Banda et al. [29], prior to each sample analysis, the BDD electrode was submitted to an anodic pretreatment $(+3.0 \mathrm{~V}$ vs $\mathrm{EAg} / \mathrm{AgCl})$ for $60 \mathrm{~s}$ followed by a cathodic pretreatment $(-3.0 \mathrm{~V}$ vs $\mathrm{EAg} / \mathrm{AgCl})$ for $120 \mathrm{~s}$ using a $0.5 \mathrm{~mol} \mathrm{~L} \mathrm{~L}^{-1}$ aqueous $\mathrm{H}_{2} \mathrm{SO}_{4}$ solution as the supporting electrolyte. It is worth highlighting that this cleaning procedure needs to be performed prior to each sample analysis, i.e., BDD electrode does not have to be prepared for each measurement.

A GC electrode, previously polished using filter paper with a diamond spray (particle size $1.0 \mathrm{~mm}$, purchased from Risitec), and rinsed with plenty of water, was employed for RCA electrochemical response comparisons. Before the voltammetric measurements, the electrode was conditioned by 10 successive $\mathrm{CV}$ scans from -1.2 to $+1.4 \mathrm{~V}$ in $0.1 \mathrm{~mol} \mathrm{~L}^{-1}$ sulfuric acid at $1.0 \mathrm{~V} \mathrm{~s}^{-1}$.

All voltammetric experiments were carried out at room temperature using $\mathrm{CV}$ and SWV (direct and stripping modes). CV scans rates (v) were of $10-100 \mathrm{mV}$ $\mathrm{s}^{-1}$; the SWV used a frequency $(f)$ of $35 \mathrm{~s}^{-1}$, scan increment $(\Delta \mathrm{Es})$ of $2 \mathrm{mV}$, scan rate of $70 \mathrm{mV} \mathrm{s}^{-1}$, and pulse amplitude $(\Delta \mathrm{Ep})$ of $50 \mathrm{mV}$. For the accumulation step, the electrode was kept immersed in $3 \mathrm{~mL}$ of a sample solution under stirring (convection rate $1500 \mathrm{rpm}$ ), while leaving the potential at open circuit. An accumulation time of 120 $\mathrm{s}$ was used for the quantitative measurements.

The CV (in Figures 1A and 2A) and SW (in Figure 3) voltammograms were not background-corrected. For a better and clearer identification of the peaks, the SW voltammograms obtained in other figures were smoothed and background-corrected using the Savitzky Golay smooth function (level: 4 or 2, depending on the analytical signal noise level), and moving average with a step window of $2 \mathrm{mV}$, respectively; available in the GPES version 4.9 software.

\subsection{Recovery and Samples Preparation}

In order to evaluate the performance of the method, recovery experiments [30] were carried out by measuring RCA concentrations in three RCA samples (de-lipidated crude extract, $90 \%$ was purchased from Embrapa Algodão, Campina Grande, Paraiba state, Brazil). The samples were extracted from different castor seed cultivars (BRS Paraguaçu, Nordestina and Energia), and were purified in the laboratory as described elsewhere [11].

The RCA samples $(3 \mathrm{~mL})$ were prepared in $0.1 \mathrm{~mol}$ $\mathrm{L}^{-1} \mathrm{H}_{2} \mathrm{SO}_{4}$ aqueous sonlution ( $\left.\mathrm{pH} 1.0\right)$ and then analyzed. Recovery curves were obtained for the sample spiked with three aliquots of $10 \mu \mathrm{L}$ of $1.0 \times 10^{-5} \mathrm{~mol} \mathrm{~L}^{-1} \mathrm{RCA}-\mathrm{A}$ solution, using the standard addition method. Each sample was evaluated in triplicate.

\section{Results and Discussion}

\subsection{Electrode Characterization}

GC electrode and cathodically polarized, anodically polarized and unpolarized BDD electrodes were submitted to a CV study immersed in a $1.0 \times 10^{-3} \mathrm{~mol} \mathrm{~L}^{-1}$ $\mathrm{K}_{4}\left[\mathrm{Fe}(\mathrm{CN})_{6}\right]$ solution with $0.5 \mathrm{~mol} \mathrm{~L}^{-1}$ sulfuric acid medium. Figure $1 \mathrm{~A}$ shows the effect of those electrodes on the electrochemical response of the $\mathrm{Fe}(\mathrm{CN})_{6}{ }^{4-} \beta^{3-}$ redox couple.Traditionally, the electrochemical response of this system to $\mathrm{CG}$ electrode is already well known (green curve in Figure 1A). The reaction kinetics is strongly influenced by the different BDD pretreatments. The cathodically polarized BDD electrode (blue curve in Figure 1A) displays sharper and larger voltammetric peaks, as well as lower overvoltage values for the $\mathrm{Fe}(\mathrm{CN})_{6}^{4-} \beta^{\beta-}$ redox couple, reflecting the improved electron-transfer kinetics when compared to the anodically polarized (black curve in Figure 1A) and to the unpolarized (red curve in Figure 1A) electrode.

The cathodic pretreatment $(-3 \mathrm{~V}$ for $120 \mathrm{~s}$; after an anodic pretreatment) greatly facilitates the oxidation/ reduction reaction leading to reversible behavior with a $\triangle \mathrm{Ep}=\sim 73 \mathrm{mV}$ and a ratio of $\mathrm{Ip}, \mathrm{a} / \mathrm{Ip}, \mathrm{c}=1.05$, in module, for a scan rate of $50 \mathrm{mV} \mathrm{s}^{-1}$, as previously reported [31]. 
A)

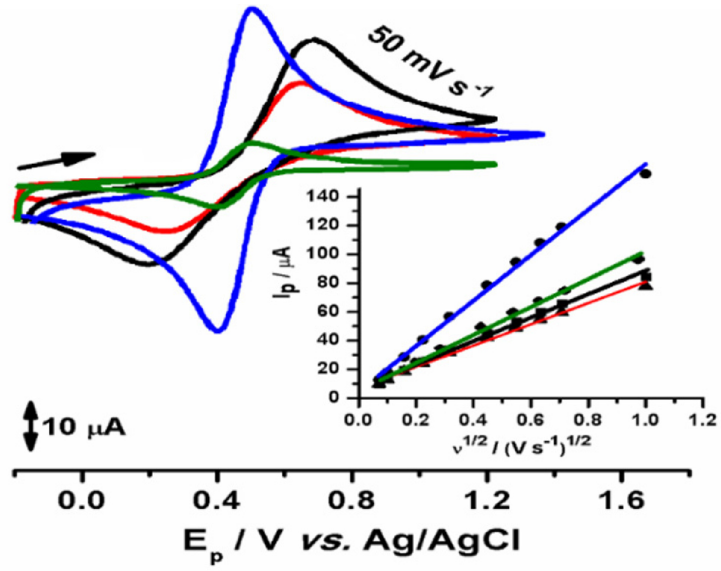

B)

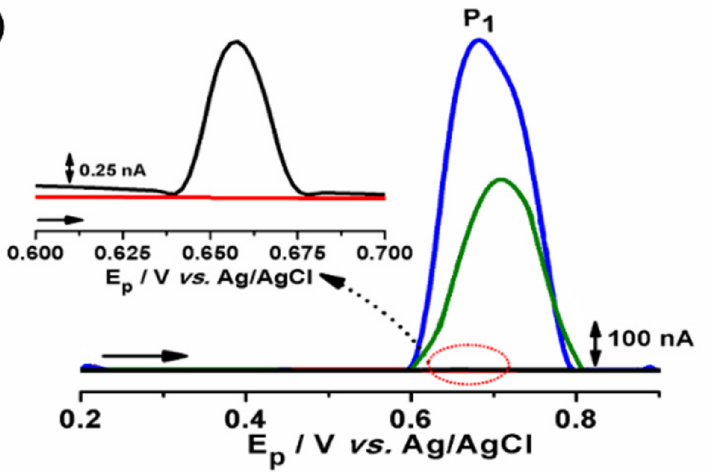

Fig. 1. (A) Cyclic voltammograms $\left(v=50 \mathrm{mV} \mathrm{s}^{-1}\right)$ and inset: the anodic peak current versus the square root of scan rate $(5-1000$ $\mathrm{mV} \mathrm{s}^{-1}$ ) curves for $1.0 \times 10^{-3} \mathrm{~mol} \mathrm{~L}^{-1} \mathrm{~K}_{4}\left[\mathrm{Fe}(\mathrm{CN})_{6}\right]$ in $0.5 \mathrm{~mol} \mathrm{~L}^{-1}$ $\mathrm{H}_{2} \mathrm{SO}_{4}$ at (-, red) unpolarized, (-) anodically polarized, and (-, blue) cathodically polarized BDD electrodes and (-, green) GC electrode. (B) Background-corrected SW voltammograms $(f=50$ $\mathrm{s}^{-1}, \Delta E_{\mathrm{s}}=2 \mathrm{mV}, \Delta E_{\mathrm{p}}=50 \mathrm{mV}$ ) for $1.3 \times 10^{-6} \mathrm{~mol} \mathrm{~L}{ }^{-1} \mathrm{RCA}-\mathrm{A}$ in $0.1 \mathrm{~mol} \mathrm{~L}^{-1}$ borate buffer $(\mathrm{pH} 9.0)$ at $(-$, red) unpolarized, (-) anodically polarized, and (-, blue) cathodically polarized BDD electrodes and (-, green) GC electrode.

On the other hand, the BDD electrode unpolarized, and the anodically pretreated $(+3 \mathrm{~V}$ for $60 \mathrm{~s})$ present electrode surfaces that did not favor the kinetics of this redox reaction, resulting in quasi-reversible behaviors with $\triangle \mathrm{Ep}$ values of 474 and $405 \mathrm{mV}$ while the Ip,a/Ip,c ratios were equal to 1.57 and $1.53 \mathrm{mV}$, respectively. Oliveira and Oliveira-Brett [31] pointed out that the slow kinetics of the redox couple is directly linked to the surface carbonoxygen functionalities (e.g. carboxyl groups) formed during anodic polarization. Similar studies were carried out applying different scan rates from 5 to $1000 \mathrm{mV} \mathrm{s}{ }^{-1}$ (figure not shown), and quasi-reversible electrochemical responses were observed for both BDD electrodes: unpolarized (average $\triangle \mathrm{Ep}$ of $533.7 \mathrm{mV}$ and a ratio Ip,a/ $\mathrm{Ip}, \mathrm{c}=2.11$ ), and anodically polarized (average $\triangle \mathrm{Ep}$ of $420.6 \mathrm{mV}$ and a ratio $\mathrm{Ip}, \mathrm{a} / \mathrm{Ip}, \mathrm{c}=2.38$ ). A reversible behavior was observed for the cathodically polarized BDD (average $\triangle \mathrm{Ep}$ of $83.1 \mathrm{mV}$, and a ratio $\mathrm{Ip}, \mathrm{a} / \mathrm{Ip}, \mathrm{c}=$ 1.04). This finding was associated with an increased electron-transfer speed due to a higher conductivity at the BDD surface. In this sense, it was interesting to evaluate the influence of the BDD surface terminations on the RCA voltammetric responses.

Regardless of the type of surface treatment employed, the anodic or cathodic peak currents increased linearly with the square root of the scan rate, suggesting that mass transfer to the electrode surface is diffusion-controlled. The influence of scan rate in relation to the square root of the anodic peak current is displayed in the inset of Figure $1 \mathrm{~A}$. The linear relations of Ipa vs $v^{1 / 2}$ are described by the equations: Ipa $(\mathrm{A})=+7.0 \times 10^{-6}+7.4 \times 10^{-5} v^{1 / 2}$ $\left(\mathrm{V} \mathrm{s}^{-1}\right)^{1 / 2}$ (unpolarized BDD, $\left.\mathrm{r}^{2}=0.9928\right)$, Ipa $(\mathrm{A})=$ $+6.7 \times 10^{-6}+8.2 \times 10^{-5} v^{1 / 2}\left(\mathrm{~V} \mathrm{~s}^{-1}\right)^{1 / 2}$ (anodically polarized BDD, $\left.\mathrm{r}^{2}=0.9919\right)$, and Ipa $(\mathrm{A})=+4.9 \times 10^{-6}+15.8 \times 10^{-5}$ $v^{1 / 2}\left(\mathrm{~V} \mathrm{~s}^{-1}\right)^{1 / 2}$ (cathodically polarized BDD, $\left.\mathrm{r}^{2}=0.9942\right)$. In addition, considering only the anodic peak current, the plot $\log$ Ip,a vs $\log v$ gave $0.39,0.41$, and 0.48 of the respective slope values for the unpolarized, anodically polarized, and cathodically polarized BDD electrodes. This confirms the diffusional process, since the slope must be equal to 0.50 for diffusion to dominate and close to 1.0 for the process to be dominated by adsorption [32].

The electroactive surface areas of the (unpolarized $\left(0.10 \mathrm{~cm}^{2}\right)$, anodically polarized $\left(0.11 \mathrm{~cm}^{2}\right)$, and cathodically polarized $\left(0.22 \mathrm{~cm}^{2}\right)$ BDD electrodes were obtained by $\mathrm{CV}$ experiments using $1.0 \times 10^{-3} \mathrm{~mol} \mathrm{~L}^{-1} \mathrm{~K}_{4}\left[\mathrm{Fe}(\mathrm{CN})_{6}\right]$ in $0.5 \mathrm{~mol} \mathrm{~L}^{-1} \mathrm{H}_{2} \mathrm{SO}_{4}$ as a probe at different scan rates (5$\left.1000 \mathrm{mV} \mathrm{s}^{-1}\right)$. Considering the anodic peak of the $\mathrm{Fe}\left(\mathrm{CN}_{6}\right)^{4-\beta^{3-}}$ redox couple, the influence for the square root of the peak current showed a linear relation in the scan rate range studied (Inset of Figure 1A), and the slopes of the equations are similar to the Randles-Sevick equation for diffusion-controlled reversible processes [32]. The cathodically polarized BDD surface area is nearly two times greater than the other electrodes. In addition, this electrode showed a similar signal (green curve in Figure 1A) to that given by a GC electrode.

\subsection{Nature of the Ricin A-chain Electrode Process}

Recently, Ribeiro et al. [9], using a GC electrode, identified two oxidation processes $(\mathrm{Ep} 1 \approx+0.28 \mathrm{~V}$ and $\mathrm{Ep} 2 \approx+0.64 \mathrm{~V}$ (vs $\mathrm{EAg} / \mathrm{AgCl})$ ) for SW voltammograms taken in borate buffer ( $\mathrm{pH} 9.0)$ for RCA that has both A and $\mathrm{B}$ chains. In the present research, the electro-activity of fresh $1.3 \times 10^{-6} \mathrm{~mol} \mathrm{~L}^{-1}$ of the ricin A-chain (RCA-A purchased from Sigma-Aldrich) solution in $0.1 \mathrm{~mol} \mathrm{~L}^{-1}$ borate buffer ( $\mathrm{pH}$ 9.0) was studied using SW voltammograms from +0.2 to $+0.9 \mathrm{~V}$ vs $\mathrm{EAg} / \mathrm{AgCl}$ employing, unpolarized (solid red curve in Figure 1B), anodically (solid black curve in Figure 1B) and cathodically polarized (solid blue curve in Figure 1B) BDD electrodes. Unpolarized presented no oxidative process, both scans polarized showed only one anodic peak and this process is in agreement with RCA electrochemical studies as carried out by Ribeiro et al. [9] using a bare GC electrode, where similar $\mathrm{Ep} 1 \approx+0.66 \mathrm{~V}$ (for anodically polarized BDD) 
and $\mathrm{Ep} 1 \approx+0.68 \mathrm{~V}$ (for cathodically polarized $\mathrm{BDD}$ ) peaks were identified as Ep2 $\approx+0.64 \mathrm{~V}$ elsewhere [9]. In order to confirm this finding, a comparative SW voltammogram was registered for the fresh $1.3 \times 10^{-6} \mathrm{~mol} \mathrm{~L}^{-1}$ RCA-A solution on a properly polished GC electrode surface, and a similar electrochemical behavior was observed at Ep1 $\approx+0.71 \mathrm{~V}$ (green curve in Figure 1B), when compared with the behavior observed at Ep1 $\approx+$ $0.68 \mathrm{~V}$ on a cathodically polarized BDD electrode (blue curve in Figure 1B).

As can be seen in Figure 1B, the BDD electrode polarization effect depends on the BDD surface termination. The RCA-A electrochemical response was taken using a cathodically polarized BDD (Ip1 $=750 \mathrm{nA})$ and is approximately seven hundred times higher than the anodically polarized BDD ( $\mathrm{Ip} 1=1.3 \mathrm{nA})$, thus justifying the use of the cathodically polarized BDD electrode in further analytical studies carried out in this report. A possible explanation for the low sensitivity of the analyte at the anodically polarized BDD electrode is that the polarization produces an excess of surface oxygen, a negative charge on the surface and an electrostatic repulsion to the electroactive species, which is possibly negatively charged as well, thus hindering electron transfer. On the other hand, the reaction is facilitated at the cathodically polarized BDD electrode due to its higher surface conductivity $[27,33,34]$.

The RCA-A oxidation process previously diagnosed with SWV (Figure 1B) was also observed in CV experiments (Inset of Figure 2A) taken in a $\mathrm{N}_{2}$ saturated $1.3 \times$ $10^{-6} \mathrm{~mol} \mathrm{~L}^{-1} \mathrm{RCA}-\mathrm{A}$ solution in $0.1 \mathrm{~mol} \mathrm{~L}^{-1}$ borate buffer (pH 9.0) on a cathodically polarized BDD electrode (forward scan: from +0.4 to $+0.9 \mathrm{~V}$ vs $\mathrm{EAg} / \mathrm{AgCl}$ ). When inverting the scan direction, no peak on the BDD electrode surface was observed, corresponding to reduction in oxidation product formation, and indicating an irreversible process.

The effect of scan rate on both the potential and peak current $\mathrm{P}_{1}$ was investigated from 10 to $100 \mathrm{mV} \mathrm{s}^{-1}$ (Figure 2A). The increase of the scan rate slightly shifts the peak potential to more positive values. The difference between peak potential Ep1 and the potential at half peak height $\mathrm{E}_{1 / 2}, \mathrm{p}_{1}$ was $66.5 \mathrm{mV}$.

For a diffusion-controlled irreversible process [35], | $\mathrm{Ep}_{1}-\mathrm{E}_{1 / 2}, \mathrm{p}_{1} \mid=47.7 /(\alpha \mathrm{na})$, it can be calculated that $\alpha \mathrm{na}=$ 0.72 , where $\alpha$ is the anodic charge transfer coefficient and $\mathrm{n}_{\mathrm{a}}$ the number of electrons in the rate-determining step. If the value of $\alpha$ is assumed to be equal to 0.5 , a value quite common for organic molecules [36], the results indicate that irreversible RCA-A oxidation involves 1 electron per molecule, which agrees with the differential pulse voltammetry studies already reported for RCA on GC electrodes $(2.2 \leq \mathrm{pH} \geq 10.2)$ [9], as well as with the SWV studies shown hereafter in the section 3.3.1. Further, the peak current $\mathrm{P}_{1}$ of RCA-A increased linearly with the square root of the scan rate (Figure $2 \mathrm{~A}$ ), according to equation: Ip1 $(\mathrm{A})=-0.67 \times 10^{-6}+10.3 \times 10^{-6} v^{1 / 2}\left(\mathrm{~V} \mathrm{~s}^{-1}\right)^{1 / 2}$. As $\mathrm{Ip}_{1} \mathrm{vs}$ $v^{1 / 2}$ plot does not pass pass through the origin of the
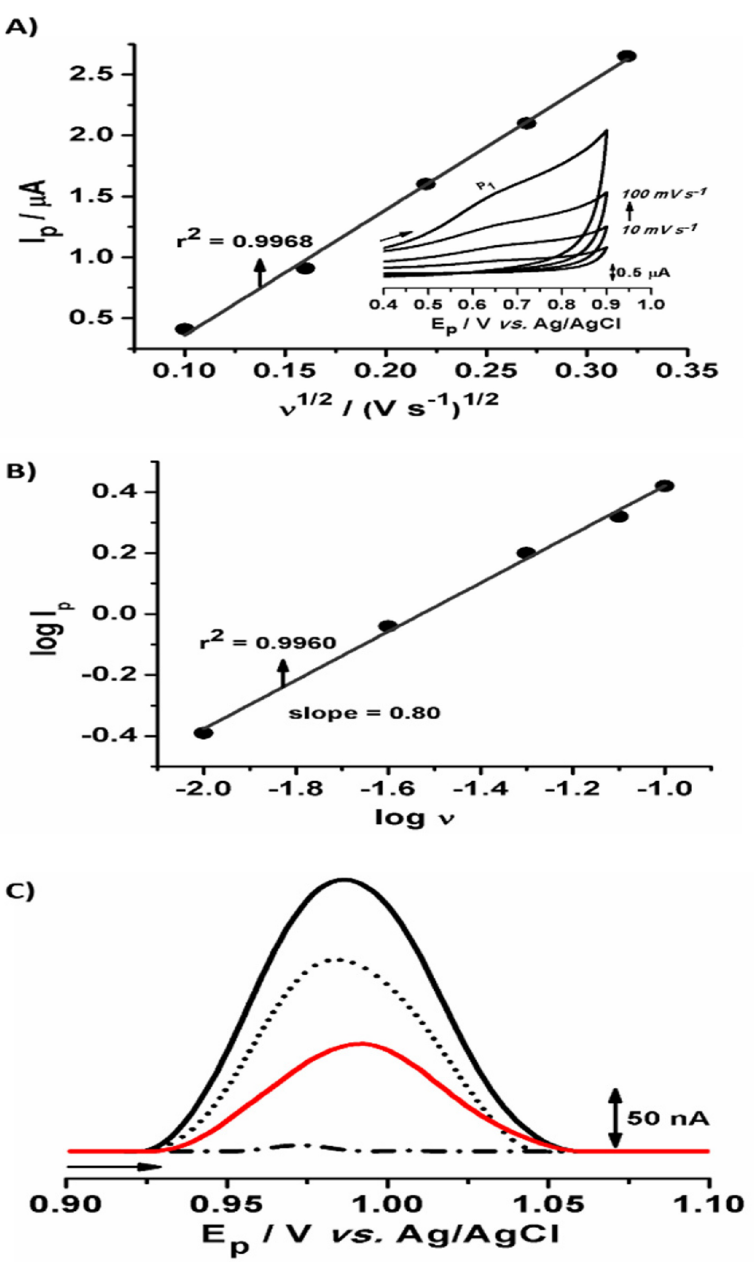

Fig. 2. (A) The anodic peak current, Ip versus the square root of scan rate, $v^{1 / 2}\left(10-100 \mathrm{mV} \mathrm{s}^{-1}\right)$ curve and inset: cyclic voltamograms for $1.3 \times 10^{-6} \mathrm{~mol} \mathrm{~L}^{-1} \mathrm{RCA}-\mathrm{A}$ in $0.1 \mathrm{~mol} \mathrm{~L}^{-1}$ borate buffer (pH 9.0). (B) $\log$ Ip $v s \log v$. (C) Background-corrected SW voltammograms $\left(f=50 \mathrm{~s}^{-1}, \Delta E_{\mathrm{s}}=2 \mathrm{mV}, \Delta E_{\mathrm{p}}=50 \mathrm{mV}\right)$ for $0.6 \times$ $10^{-6}$ mol L ${ }^{-1} \mathrm{RCA}-\mathrm{A}$ on a cathodically polarized BDD electrode:

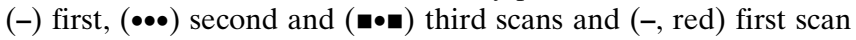
after transferring the electrode to sulfuric acid ( $\mathrm{pH}$ 1.0) and rinsing the electrode with ultrapure water.

points, this indicates that the reaction is not diffusioncontrolled process [32]. On the other hand, RCA-A is giant molecule [2] leading to inconclusive interpretations of the experimental data based on diffusion coefficients. RCA-A consists of many amino acid residues [2] organizing differently on the electrode surfaces, and impairing an accurate understanding of its mass transport. As can be seen in Figure 2B, the $\log$ Ip vs $\log v$ plot gave a slope of 0.80 for peak $\mathrm{P}_{1}$ suggesting an adsorption-controlled process [32]. So, an adsorption test was carried out to investigate this phenomenon. Afterwards, three SW scans were recorded in the solution containing RCA-A (solid, dotted and dash-dot black curves in Figure 2C), the electrode was well washed with deionized water and reimmersed in a sulfuric acid solution ( $\mathrm{pH}$ 1.0). Thereafter, 
an RCA-A peak (red curve in Figure 2C) appears, thus confirming the adsorption of the RCA-A (or its nonelectroactive oxidation products) on the BDD electrode surface. This adsorption can be used as a pre-concentration step, thus suggesting the possibility of setting up an eletroanalytical method to determine RCA-A by AdSV. However, the surface of the BDD electrode can be regenerated by applying the pretreatments established in section 2.2.
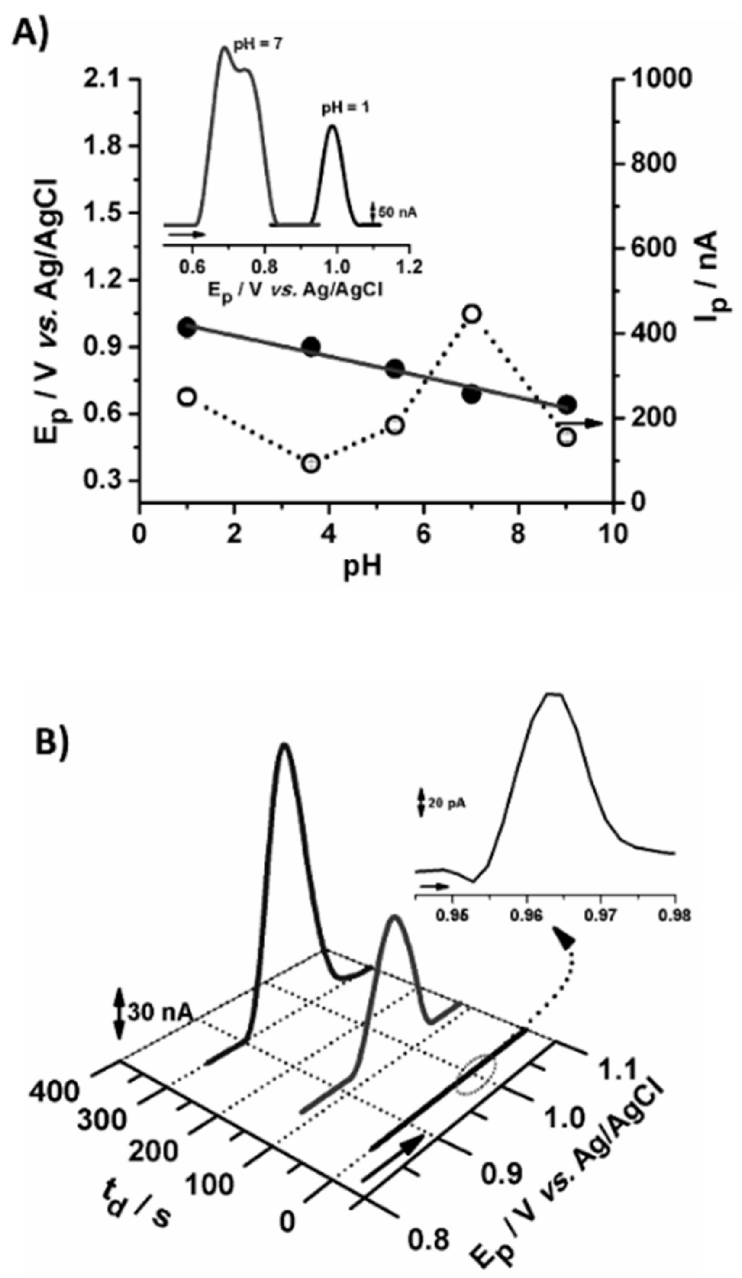

Fig. 3. (A) Potential (O) and $(\bigcirc)$ current peak versus $\mathrm{pH}$ and the background-corrected SW voltammograms from +0.2 to $+0.9 \mathrm{~V}$ (inset) taken in $0.6 \times 10^{-6} \mathrm{~mol} \mathrm{~L}{ }^{-1} \mathrm{RCA}-\mathrm{A}$ solutions in different electrolytes and $\mathrm{pH}$ ranging from 1.0 to 9.0 on a cathodically polarized BDD electrode. (B) 3D plots of background-corrected SW voltammograms obtained in $0.025 \times 10^{-6} \mathrm{~mol} \mathrm{~L}^{-1} \mathrm{RCA}-\mathrm{A}$ dissolved in sulfuric acid without $\left(t_{d}=0 \mathrm{~s}\right.$, inset $)$ and with $\left(t_{d}=120\right.$ $\mathrm{s}$ and $300 \mathrm{~s}$ ) pre-concentration in open circuit on a cathodically polarized BDD electrode. $\left(f=50 \mathrm{~s}^{-1}, \Delta E_{\mathrm{s}}=2 \mathrm{mV}, \Delta E_{\mathrm{p}}=50 \mathrm{mV}\right)$.

\section{$3.3 \mathrm{pH}$ Effect}

Figure 3A displays potential and current peak versus $\mathrm{pH}$ curves obtained of the background-corrected SW voltammograms taken in $0.6 \times 10^{-6} \mathrm{~mol} \mathrm{~L}{ }^{-1} \mathrm{RCA}-\mathrm{A}$ solutions in different electrolytes and $\mathrm{pH}$ ranging from 1.0 to 9.0 at a cathodically polarized BDD electrode.

As can be seen in inset of Figure 3A, there is a voltammetric overlapping of two peaks possibly associated with two oxidation steps at this $\mathrm{pH}$ that might compromise the selectivity of the method. On the other hand, a well-defined RCA-A peak was found when a sulfuric acid $0.1 \mathrm{~mol} \mathrm{~L}^{-1}$ solution ( $\mathrm{pH} 1.0$ ) was used as the supporting electrolyte. Thus, this medium was chosen for future electroanalytical studies since it represented a good compromise between sensitivity and selectivity.

The potential $\mathrm{Ep}_{1}$ is shifted to more negative values and displays a linear dependence with increasing $\mathrm{pH}$. This suggest that the oxidation of the molecule, under the experimental conditions depends on $\mathrm{pH}$ and involves protonation of the electroactive RCA-A site; thus affecting the overall reaction mechanism. The $\mathrm{Ep}_{1} \mathrm{vs} \mathrm{pH}$ linear relation has a slope of $-46.0 \mathrm{mV} / \mathrm{pH}$ for peak, thus the number of protons $\left(\mathrm{H}^{+}\right)$per molecule can be estimated at 1 , using the equation $\Delta \mathrm{E}(\mathrm{mv}) / \Delta \mathrm{pH}=-59 \mathrm{H}^{+} / \alpha \mathrm{n}$, and a ana value of 1.6 (from the slope of Ep vs $\log f$ discussed below), indicating an irreversible reaction mechanism with the transfer of one electron and one proton for the rate-determining step [37].

Electroactive centers in high molecular weight molecules, such as RCA, arise from their constituent amino acids. The key to understanding the electrochemical processes of such molecules is amino acid electrochemical oxidation itself. The amino acids Leucine, Arginine, Alanine, Glutamic acid and Aspartic acid are not electroactive [38], yet Cysteine [21,22], Methionine [21,22], Tryptophan [21,39], Tyrosine [21] and Histidine [21] have already been oxidized at GC and/or BDD electrode surfaces, as shown in Table 1. On both electrode surfaces, the electroactive amino acids Tryptophan and Tyrosine $[21,39]$ are similar to the electrochemical behavior of RCA and RCA-A molecules in phosphate buffer $(\mathrm{pH}$ 7.0). Thus, the electroactive response of RCA-A may well be associated with these amino acids.

At $\mathrm{pH}$ 7.0, SW voltammogram (inset in Figure 3A) shows only one oxidation step (P1) for RCA-A, occurring at $+0.71 \mathrm{~V}$, which may match the oxidation of Tryptophan $(+0.69 \mathrm{~V})$ and Tyrosine $(+0.65 \mathrm{~V})$ residues when a GC electrode is used (Table 1). On the other hand, using a BDD electrode (at the same potential window) the oxidation step of RCA-A appears at $+0.75 \mathrm{~V}$ vs EAg/ $\mathrm{AgCl}$, consistent with peak $\mathrm{P}_{1}$ of the poly-Tryptophan $(+$ $0.75 \mathrm{~V}$ ) residues. Thus, the peak $\mathrm{P}_{1}$ of the RCA-A may agree with the oxidation of Tryptophan residues using the BDD electrode. Further, the oxidation step peak $\mathrm{P}_{2}$ for RCA $(+0.70 \mathrm{~V})$ in previous paper [9] may correspond to the oxidation of RCA-A (peak $\mathrm{P}_{1}$, Figure 1 and 2), with a 
Table 1. Peak oxidation potentials of RCA electroactive amino acids on GC and BDD electrodes using DPV.

\begin{tabular}{|c|c|c|c|c|c|c|}
\hline Compound & $\begin{array}{l}\text { GC electrode } \\
\mathrm{P}_{1}(\mathrm{~V})\end{array}$ & $\mathrm{P}_{2}(\mathrm{~V})$ & Ref. & $\begin{array}{l}\text { BDD electrode } \\
\mathrm{P}_{1}(\mathrm{~V})\end{array}$ & $\begin{array}{l}\text { Ref. } \\
\mathrm{P}_{2}(\mathrm{~V})\end{array}$ & \\
\hline Cysteine & 0.53 & 0.88 & {$[21,22]$} & 0.55 & 0.81 & {$[21,22]$} \\
\hline Methionine & - & 1.27 & {$[21,22]$} & - & - & - \\
\hline Tryptophan & 0.69 & 1.00 & {$[21,39]$} & ${ }^{a} 0.75$ & ${ }^{a} 1.10$ & {$[21]$} \\
\hline Tyrosine & 0.65 & - & [21] & ${ }^{b} 0.65$ & - & [21] \\
\hline Histidine & 1.18 & - & [21] & ${ }^{c} 1.28$ & - & [21] \\
\hline RCA & 0.38 & 0.70 & [9] & - & - & - \\
\hline RCA-A & ${ }^{d} 0.71$ & - & This work & ${ }^{d} 0.75$ & - & This work \\
\hline
\end{tabular}

${ }^{[a]}$ Measurement using poly-tryptophan. ${ }^{[\mathrm{b}]}$ Measurement using poly-tyrosine. ${ }^{[\mathrm{c}]}$ Measurement using the first CV scan. ${ }^{[\mathrm{d}]}$ Measurement using the first SWV scan.

potential peak of around $+0.71 \mathrm{~V}$ using a GC electrode or of $+0.75 \mathrm{~V}$ using a BDD electrode.

Since the phenol and indole groups present in Tyrosine and Tryptophan structures can be electro-oxidized, Tyrosine oxidation occurs in the hydroxyl group and includes formation of a thermodynamically unstable radical. This radical's stabilization results in the formation of an electroactive ortho-quinone, reducing to catechol. Tryptophan oxidation begins with the oxidation of the pyrrole ring. The oxidation of Tryptophan (indole-derivative with a substituent at $\mathrm{C} 3$ position) to 2-oxyindoles corresponds to the oxidation (on C2) of the pyrrole ring $[21,39]$.

\subsection{Accumulation Time Effect}

The RCA-A adsorption capacity was evaluated on the electrode surface at open circuit using two different accumulation times (120 s and $300 \mathrm{~s})$. The SW voltammograms (Figure 3B) display the following characteristics for RCA-A oxidation according to the accumulation time: $\mathrm{td}=0 \mathrm{~s}(\mathrm{Ep}=0.963 \mathrm{~V}$ and $\mathrm{Ip}=0.2 \mathrm{nA}), \mathrm{td}=120 \mathrm{~s}(\mathrm{Ep}=$ $0.978 \mathrm{~V}$ and $\mathrm{Ip}=87 \mathrm{nA})$, and $\mathrm{td}=300 \mathrm{~s}(\mathrm{Ep}=0.967 \mathrm{~V}$ and $\mathrm{Ip}=170 \mathrm{nA}$ ). A pre-concentration time of $120 \mathrm{~s}$ represented a good combination between sensitivity and overall time of analysis. Thus, strong RCA-A adsorption on the electrode surface with pre-concentration made possible the consequent development of a method of analysis for trace level determinations using adsorptive stripping voltammetry.

SW voltammograms (direct and stripping modes, Figure 4) taken in differing concentrations of RCA-A in both strongly acid $(\mathrm{pH}$ 1.0, Figure 4A) and physiological $(\mathrm{pH}$ 7.0, Figure 4B) medium showed similar outcomes at a cathodically polarized BDD electrode. These data help to clarify the charge transfer reaction of the RCA-A seen in the $\mathrm{CV}$ experiments (Figure 2A). The decomposition of the total current on the forward and backward components revealed contributions of the forward current alone for the oxidation process. Therefore, confirming the irreversibility of the system for both assay $\mathrm{pH}$ values.
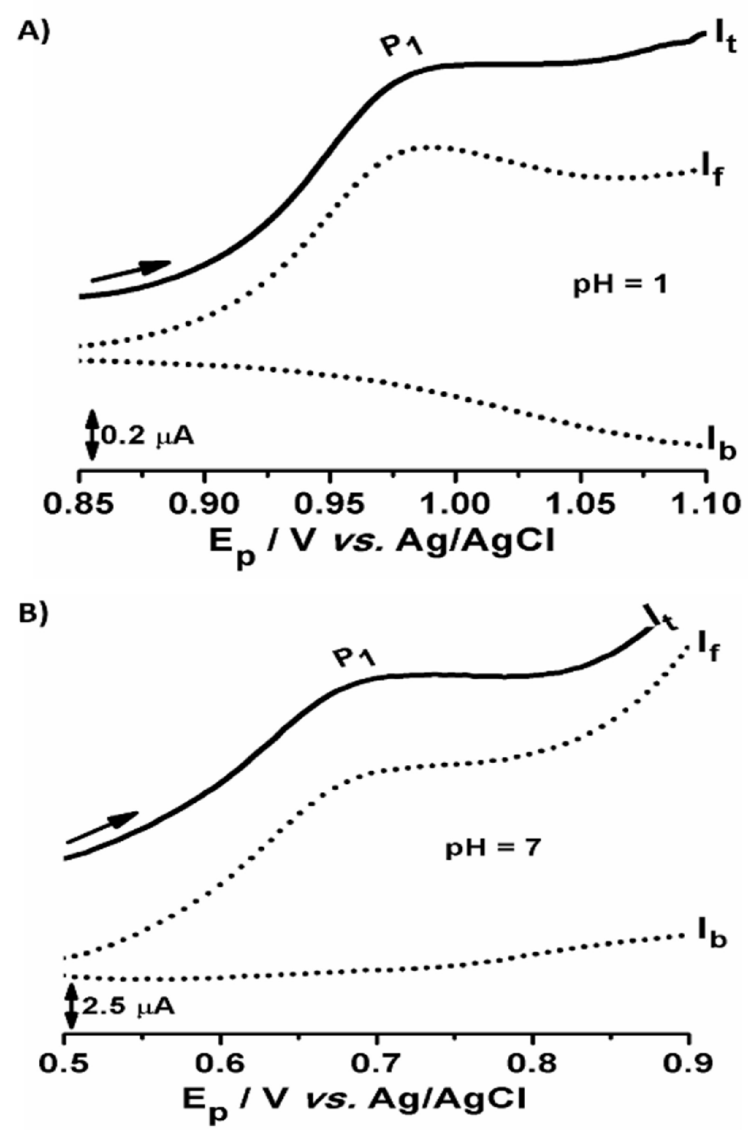

Fig. 4. SW voltammograms $\left(f=35 \mathrm{~s}^{-1}, \Delta E_{\mathrm{s}}=2 \mathrm{mV}, \Delta E_{\mathrm{p}}=50 \mathrm{mV}\right.$ and td (open circuit) $=120 \mathrm{~s}$ ) taken on a cathodically polarized BDD electrode. (A) $1.3 \times 10^{-6} \mathrm{~mol} \mathrm{~L}{ }^{-1} \mathrm{RCA}-\mathrm{A}$ in $0.1 \mathrm{~mol} \mathrm{~L}^{-1}$ phosphate buffer (pH 7.0). $f=50 \mathrm{~s}^{-1}, \Delta E_{\mathrm{s}}=2 \mathrm{mV}, \Delta E_{\mathrm{p}}=50 \mathrm{mV}$. (B) $0.1 \times 10^{-6} \mathrm{~mol} \mathrm{~L}{ }^{-1} \mathrm{RCA}-\mathrm{A}$ in $0.1 \mathrm{~mol} \mathrm{~L}^{-1}$ sulfuric acid $(\mathrm{pH}$ 1.0). Total $\left(I_{\mathrm{t}}\right)$, forward $\left(I_{\mathrm{f}}\right)$ and backward $\left(I_{\mathrm{b}}\right)$ currents.

\subsection{Analytical Determination of RCA-A by SWAdSV}

In order to determine the best analysis conditions considering the peak potential and current, the scan parameters for SWAdSV were investigated in univariate studies. 


\subsubsection{Optimization of SWAdSV Conditions}

The experimental parameters $(f, \triangle \mathrm{Es}$, and $\Delta \mathrm{Ep})$ of the SWAdSV technique were systematically optimized before the analytical investigations. Generally, these scan parameters strongly influence the peak current (intensity) and the selectivity (half-peak width) in SWV, thus determining the sensitivity of the technique. Table 2 displays the optimized values of the SWV parameters obtained for RCA-A determinations.

Table 2. Investigated SWAdSV parameters and their optimum values obtained for RCA-A determining.

\begin{tabular}{lll}
\hline Parameters & Studied range & Optimum value \\
\hline $\mathrm{pH}$ & $1.0-11.8$ & 1.0 \\
Deposition time $^{a} \mathrm{t}_{\mathrm{d}}(\mathrm{s})$ & $0-300$ & 120 \\
${\text { Frequency, } f\left(\mathrm{~s}^{-1}\right)}_{\text {Scan increment, } \Delta \mathrm{Es}(\mathrm{mV})}$ & $10-50$ & 35 \\
Pulse amplitude, $\Delta \mathrm{Ep}(\mathrm{mV})$ & $25-50$ & 2 \\
\hline
\end{tabular}

${ }^{[a]}$ In open circuit.

The influence of the $f$ parameter on the electrochemical oxidation of RCA-A was studied in a range of 10 to $50 \mathrm{~s}^{-1}$. In this $f$ range, the current peak $\mathrm{P}_{1}$ displayed a linear dependence with frequency (relation: Ip1 $(\mathrm{nA})=$ $\left.-2.25+0.22 f\left(\mathrm{~s}^{-1}\right) ; \mathbf{R}^{2}=0.995\right)$, suggesting an irreversible and diffusional system whose oxidation process is controlled by adsorption of RCA-A on the BDD electrode surface. This was also confirmed by the non-linear relation of the peak current to frequency (square root of frequency) (relation: Ip1 $(\mathrm{nA})=-0.34-0.82 f^{1 / 2}\left(\mathrm{~s}^{-1}\right)^{1 / 2}+$ $\left.0.31\left(f^{1 / 2}\right)^{2}\left(\mathrm{~s}^{-1}\right) ; \mathrm{R}^{2}=0.994\right)$. The adsorption of RCA-A at a cathodically polarized BDD electrode justified the preconcentration studies presented above, and allowed studies at low concentrations. A slope value of $36 \mathrm{mV}$ was obtained for the linear relation of Ep1 vs $\log f$. Using the Lovric equation $(\triangle \mathrm{Ep} / \triangle \log f=-59(\mathrm{mV}) / \alpha$ na $)[36]$, a $\alpha$ na value of 1.6 was estimated.

The scan rate in SWAdSV is the product of $f$ and $\Delta E s$. Thus, the $\Delta$ Es parameter was investigated in a range from 2.0 to $5.0 \mathrm{mV}$. The higher sensitivity was achieved at $2 \mathrm{mV}$ $(\mathrm{Ip} 1=5.8 \mathrm{nA})$ and a significant loss of peak current was observed in $5 \mathrm{mV}(\mathrm{Ip} 1=1.1 \mathrm{nA})$, which justifies the use of $2 \mathrm{mV}$ for the studies that followed. Moreover, a practically linear dependence was observed for the peak potential $(\mathrm{Ep} 1 \approx+0.98 \mathrm{~V})$. In this optimized condition, electrochemical RCA-A oxidation was investigated for two $\Delta \mathrm{Ep}$ values $(25$ and $50 \mathrm{mV}$ ). Although a current maximum had been observed at $25 \mathrm{mV}(\mathrm{Ip} 1=8.6 \mathrm{nA}$; peak width at half height $\left(\mathrm{W}_{1 / 2}\right)=71 \mathrm{mV}$ ), a peak overlap was observed and we decided to work with $50 \mathrm{mV}$ (Ip1= $5.8 \mathrm{nA} ; \mathrm{W}_{1 / 2}=43 \mathrm{mV}$ ) due to the better selectivity for RCA-A oxidation.

Considering the optimum values of $\Delta \mathrm{Es}, \Delta \mathrm{Ep}$, and using the slope of the relationship between Ip vs $f$, an approximate calculation of the surface concentration $(\Gamma)$ of the RCA adsorbed species on the electrode surface is given by $\operatorname{Ip} 1=(5 \pm 1) \times 10^{2} \mathrm{q} \alpha \mathrm{n}^{2} \mathrm{~F} \Delta \mathrm{Es} \Delta \mathrm{Ep} \Gamma f[40,41]$, where $\mathrm{q}$ is the electrode area, and $\mathrm{F}$ is the Faraday constant, and the other terms have already been defined in this report. For this calculation, the value for $\Gamma$ was $9.9 \times 10^{-11} \mathrm{~mol} \mathrm{~cm}^{-2}$.

\subsubsection{Analytical Curve and Figures of Merit}

Figure 5 displays the background-corrected SWAdS voltammograms and the analytical curve for process P1 of the RCA-A at a cathodically polarized BDD electrode. The adsorption of RCA-A on the BDD electrode is presented above (Figure 2C and Figure 3B). A potential around $+0.98 \mathrm{~V}$ was identified for the RCA-A peak and a good linear relation between peak current and concentration was verified for concentration in the range of $(3.3$ - 94.0 $) \times 10^{-9} \mathrm{~mol} \mathrm{~L}^{-1}\left(\mathrm{Ip} 1 / \mu \mathrm{A}=1.16( \pm 0.009)+6.1 \times 10^{6}\right.$ $\left( \pm 0.2 \times 10^{6}\right)[$ RCA-A $] / \mathrm{mol} \mathrm{L}^{-1}$ and $\mathrm{R}^{2}=0.9944$ for $\left.\mathrm{n}=6\right)$. However, the voltammograms and the points in the calibration curve at higher concentrations than $94 \times 10^{-9}$ mol L ${ }^{-1}$ show that electrode saturation occurred.

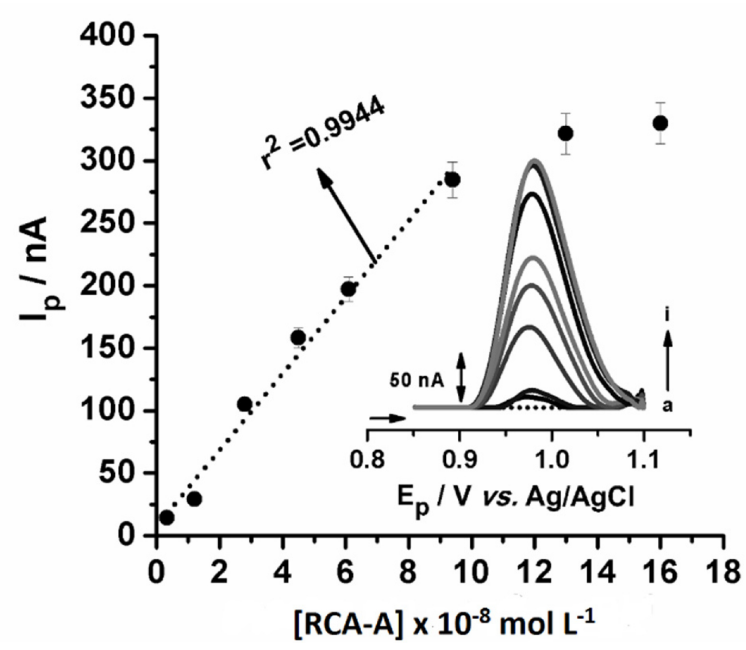

Fig. 5. Analytical curve for RCA-A. Inset: the backgroundcorrected SWAdS voltammograms $\left(f=35 \mathrm{~s}^{-1}, \Delta E_{\mathrm{s}}=2 \mathrm{mV}, \Delta E_{\mathrm{p}}=\right.$ $50 \mathrm{mV}$, and $\mathrm{t}_{\mathrm{d}}$ (open circuit) $=120 \mathrm{~s}$ ) for additions of RCA-A in $0.1 \mathrm{~mol} \mathrm{~L}^{-1}$ sulfuric acid ( $\left.\mathrm{pH} 1.0\right)$ on the cathodically polarized BDD electrode. (a) 0, (b) 3.3, (c) 17.0, (d) 28.0, (e) 45.0, (f) 61.0, (g) 94.0, (h) 130.0 , and (i) $160.0\left(\times 10^{-9} \mathrm{~mol} \mathrm{~L}^{-1}\right)$.

Between measurements, a scan without pre-concentration was done in the same RCA-A solution, which ensured a better regeneration of the BDD surface.

A LOD of $6.2 \times 10^{-10} \mathrm{~mol} \mathrm{~L}^{-1}\left(19.0 \mu \mathrm{g} \mathrm{L}^{-1}\right)$ and a limit of quantification (LOQ) of $2.1 \times 10^{-9} \mathrm{~mol} \mathrm{~L}^{-1}\left(62.0 \mu \mathrm{g} \mathrm{L}^{-1}\right)$ were calculated using $\mathrm{kSd} / \mathrm{b}$, where $\mathrm{k}=3$ for LOD and $\mathrm{k}$ $=10$ for $\mathrm{LOQ}, \mathrm{Sd}$ is the standard deviation of the blank signal $(\mathrm{Sd}=0.0015 \mu \mathrm{A} ; \mathrm{n}=10)$, and $\mathrm{b}$ is the sensitivity (slope) of the analytical curve [42]. 
Table 3 compares, in terms of LOD, the analytical performance of the developed voltammetric methods and previously reported methodologies for RCA determination [9,43-54]. The intense RCA adsorption onto the cathodically polarized BDD surface allowed that the proposed SWAdSV method is more sensitive than other techniques. A LOD was around 168 times lower than that obtained by using SWV with a GC electrode [9]. In addition, without the pre-concentration on the cathodically polarized DDB electrode, SW voltammogram showed a higher current sensitivity than the CGE for the determination of RCA (see inset in Figure 3B and previous work [9]). However, the LOD determined in our study is higher than the LOD found by Suresh and colleagues $[44,45]$ for RCA determining in water samples using amperometric immunosensors (sandwich-ELISA) based on carbon nanotubes $\left(\mathrm{LOD}=0.56 \mu \mathrm{g} \mathrm{\textrm {L } ^ { - 1 }}\right)$, or graphite $\left(\mathrm{LOD}=1.7 \mu \mathrm{g} \mathrm{L}^{-1}\right)$, or gold nanoparticles/nanotubes/chitosan $\left(\mathrm{LOD}=2.1 \mu \mathrm{g} \mathrm{L}^{-1}\right)$. On the other hand, it is worth highlighting that a smaller LOD might still be achieved using SWAdSV with higher accumulation times, e.g. $300 \mathrm{~s}$ (Figure 3B).

Table 3. A comparison between the LOD values taken from published RCA determination methodologies, and this study (Adapted from Musshoff and Madea ${ }^{[3]}$ ).

\begin{tabular}{lll}
\hline Detection technique & $\begin{array}{l}\text { LOD/ } \\
(\mu \mathrm{g}\end{array}$ & Ref. \\
& $\left.\mathrm{L}^{-1}\right)$ & \\
\hline $\begin{array}{l}\text { Amperometric imunosensors: polystyrene/ } \\
\text { graphite }\end{array}$ & 40 & {$[43]$} \\
Amperometric imunosensors: carbon nanotubes & 0.56 & {$[44]$} \\
Amperometric imunosensors: gold nanoparti- & 2.1 & {$[45]$} \\
cules/nanotubes/chitosan & & \\
Amperometric imunosensors: graphite & 1.7 & {$[44]$} \\
Quartz crystal microbalance sensors & 5000 & {$[46]$} \\
Fluoroimmunoassay & 1000 & {$[47]$} \\
Biosensor assay & 320 & {$[48]$} \\
Lateral flow devices & 250 & {$[49]$} \\
ELISA & 80 & {$[50]$} \\
Inhibition of lysozyme & 80 & {$[51]$} \\
Immunochromatographic assay & 50 & {$[52]$} \\
Immunocapture coupled with LC-MALDI MS & 50 & {$[53]$} \\
ELISA with colorimetric measurement & 40 & {$[54]$} \\
SWV/GC & 3200 & {$[9]$} \\
SWAdSV/BDD & 19 & This \\
& & work \\
\hline
\end{tabular}

While some methods reported in the literature (Table 3) present a best specificity, selectivity, LODs, as well as good electrochemical properties of the electrode materials (nanotubes, chitosan, and gold nanoparticles), when compared to the proposed SWAdSV method, these methodologies are laborious, expensive and include several steps (electrode preparation, RCA purification, preparation of toxoid, and antibody raising, RCA immunosensing and detection, and biochemical testing). Moreover, the high sensitivity, and the low LOD and analysis time demonstrate both the feasibility and applicability of the developed methodology for RCA determining in differing samples such as biological fluids or tissues, in environmental, beverage or food matrices, or in the prevention of the deliberate (or not) low concentration contamination of systems with this toxic compound.

\subsubsection{Analytical Applications and Recovery Tests}

The proposed SWAdSV method was applied to RCA determination in three de-lipidated crude RCA samples extracted from differing castor seed cultivars (BRS Paraguaçu, Nordestina and Energia). RCA was detected (Ep $\approx 0.96 \mathrm{~V}$ in $\mathrm{pH} 1.0$ ) in all samples at levels ranging from $2.1 \times 10^{-9} \mathrm{~mol} \mathrm{~L}^{-1}$ to $3.9 \times 10^{-9} \mathrm{~mol} \mathrm{~L}^{-1}$, as shown in Table 4.

For all of the samples, the BDD electrode responded efficiently to incremental RCA-A (using the standard addition method), presenting an overall average recovery from $99.2 \pm 1.6 \%$ for the three different RCA-A concentration levels in the real samples studied (Table 4). The results revealed sufficient accuracy, and therefore the possibility of using the proposed analytical RCA determination method for quality control in real samples.

\section{Conclusions}

An irreversible electrochemical RCA oxidation peak was identified on the cathodically polarized BDD electrode by different voltammetric techniques using both direct and adsorptive stripping modes. An adsorption-controlled $\mathrm{pH}$ dependent process was observed with transfer of one electron and one proton for values of $1.0 \leq \mathrm{pH} \leq 9.0$, and the RCA oxidation step may well correspond to the oxidation of tryptophan amino acid residues. Further, the analytical results obtained in this work demonstrate the potential of BDD electrodes using SWAdSV experiments for RCA quantification. A linear response ranging from (3.3 to 94.0$) \times 10^{-9} \mathrm{~mol} \mathrm{~L}^{-1}\left(\mathrm{r}^{2}=0.9944\right)$ was accomplished with an estimated limit of detection of $6.2 \times 10^{-10} \mathrm{~mol} \mathrm{~L}^{-1}$, and mean average recoveries above $95 \%$ using a short deposition time in open circuit (120 s). The LOD is lower than several methods found in the literature (e.g. 168 times lower than a previous square wave voltammetric method using a glassy carbon electrode). A smaller LOD might still be achieved by using the proposed SWAdSV method with longer pre-concentration time. However, the use of accumulation time of $120 \mathrm{~s}$ was sufficient to determine RCA-A in the analyzed samples without impair the analyses time. On the other hand, lower LODs might be useful for RCA-A determining in samples with lower concentration levels.

The study herein developed opens up the opportunity for RCA-A detection in samples with trace levels of RCA and/or its isoforms; to prevent deliberate (or otherwise) contamination of systems with this toxic compound. 
Table 4. Results obtained using the proposed voltammetric method for the determination of RCA in various RCA samples.

\begin{tabular}{|c|c|c|c|c|}
\hline \multirow{2}{*}{$\begin{array}{l}\text { RCA } \\
\text { Samples }\end{array}$} & \multicolumn{2}{|c|}{$\mathrm{RCA}-\mathrm{A} /\left(\times 10^{-9} \mathrm{~mol} \mathrm{~L}^{-1}\right)$} & \multirow{2}{*}{$\begin{array}{l}\text { Recovery }{ }^{a} \\
(\%)\end{array}$} & \multirow{2}{*}{$\begin{array}{l}\text { Average recovery } \pm \mathrm{RSD}^{[b]} \\
(\%)\end{array}$} \\
\hline & Added & Found $\pm \mathrm{RSD}^{b}$ & & \\
\hline \multirow{4}{*}{ Paraguaçu Cultivar } & - & $2.1 \pm 0.13$ & - & \multirow[t]{2}{*}{-} \\
\hline & 33.0 & $32.8 \pm 3.03$ & 99.2 & \\
\hline & 66.0 & $64.7 \pm 2.84$ & 98.1 & $99.0 \pm 1.04$ \\
\hline & 99.0 & $99.1 \pm 0.40$ & 100.1 & \\
\hline \multirow{4}{*}{ Nordestina Cultivar } & - & $3.0 \pm 0.06$ & - & \multirow[t]{2}{*}{-} \\
\hline & 33.0 & $32.5 \pm 1.36$ & 98.5 & \\
\hline & 66.0 & $66.2 \pm 3.49$ & 100.3 & \multirow[t]{2}{*}{$98.9 \pm 1.14$} \\
\hline & 99.0 & $97.1 \pm 3.45$ & 98.1 & \\
\hline \multirow{4}{*}{ Energia Cultivar } & - & $3.9 \pm 1.05$ & - & \multirow[t]{2}{*}{-} \\
\hline & 33.0 & $33.9 \pm 1.95$ & 102.6 & \\
\hline & 66.0 & $64.5 \pm 2.31$ & 97.7 & \multirow[t]{2}{*}{$99.7 \pm 2.54$} \\
\hline & 99.0 & $97.9 \pm 2.25$ & 98.9 & \\
\hline
\end{tabular}

${ }^{[a]}(100 \times$ Found/Added $) .{ }^{[b]}$ RSD $=$ Relative standard deviation $(n=3)$.

\section{Acknowledgements}

The authors would like to thank the Brazilian agencies CNPq and CAPES (Grants: CNPq - UNIVERSAL 477084/2013-3, 304419/2015-0 and 475879/2009-0, CAPES/ Mincyt REDE 015/14) for scholarships and financial support for this work. The authors also thank Embrapa Algodão (Brazil - Campina Grande/PB) for RCA samples.

\section{References}

[1] J. M. Lord, L. M. Roberts, J. D. Robertus. FASEB J. 1994, 8, 201-208.

[2] UniProtKB P02879 (RICI_RICCO). Available at: http:// www.uniprot.org/uniprot/P02879 (Accessed: 15th April 2016).

[3] F. Musshoff, B. Madea. Drug Test. Anal. 2009, 1, 184-191.

[4] A. Periyakaruppan, P. U. Arumugam, M. Meyyappan, J. E. Koehne. Biosens. Bioelectron. 2011, 28, 428-433.

[5] B. Y. Liu, K. W. Lee. Am. Ind. Hyg. Assoc. J. 1975, 36, 861865.

[6] G. D. Griffiths, P. Rice, A. C. Allenby, S. C. Bailey, D. G. Upshall. Inhal. Toxicol. 1995, 7, 269-288.

[7] G. D. Griffiths. Toxins. 2011, 3, 1373-1392.

[8] DELAWARE HEALTH AND SOCIAL SERVICES. Ricin toxin. Available at: http://dhss.delaware.gov/dhss/dph/files/ ricintoxinlab.pdf (Accessed: 12th October 2016).

[9] W. F. Ribeiro, D. J. E. da Costa, A. S. Lourenço, I. C. Lopes, E. P. de Medeiros, G. R. Salazar-Banda, V. B. do Nascimento, M. C. U. de Araujo. Analyst. 2013, 138, 4565-4573.

[10] J. H. T. Luong, K. B. Male, J. D. Glennon. Analyst. 2009, 134, 1965-1979.

[11] Y. Einaga. J. Appl. Electrochem. 2010, 40, 1807-1816.

[12] K. Pecková, J. Musilová, J. Barek. Crit. Rev. Anal. Chem. 2009, 39, 148-172.

[13] L. S. Andrade, G. R. Salazar-Banda, O. Fatibello-Filho, R. C. Rocha-Filho, Chapter 8 Cathodic Pretreatment of borondoped diamond electrodes and their use in electroanalysis, 1sted., Synthetic Diamond Films: Preparation, Electrochemistry, Characterization and Applications, vol. 8, John Wiley \& Sons, Inc, San Francisco, 2011, pp. 181-212.

[14] A. Kraft. Int. J. Electrochem. Sci. 2007, 2, 355-385.
[15] D. J. E. C, J. C. S. Santos, F. A. C. S. Brandão, W. F. Ribeiro, G. R. Salazar-Banda, M. C. U. Araujo. J. Electroanal. Chem. 2017, 789, 100-107.

[16] M. Chiku, K. Horisawab, N. Doib, H. Yanagawab, Y. Einaga. Biosens. Bioelectron. 2010, 26, 235-240.

[17] E. Fortin, J. Chane-Tune, P. Mailley, S. Szunerits, B. Marcus, J. P. Petit, M. Mermoux, E. Vieil. Bioelectrochemistry. 2004, 63 (1-2), 303-306.

[18] J. Zhang, M. Oyama. Microchem. J. 2004, 78 (2), 217-222.

[19] S. Haymond, G. T. Babcock, G. M. Swain. J. Am. Chem. Soc. 2002, 124, 10634-10635.

[20] G. S. Garbellini, C. V. Uliana, H. Yamanaka. J. Braz. Chem. Soc. 2011, 22 (7), 1241-1245.

[21] T. A. Enache and A. M. Oliveira-Brett. Bioelectrochemistry. 2013, 89, 11-18.

[22] T. A. Enache, A. M. Oliveira-Brett. Bioelectrochemistry. 2011, 81, 46-52.

[23] G. Zhao, Y. Qi, Y. Tian. Electroanalysis. 2006, 18 (8), 830834.

[24] H. B. Suffredini, V. A. Pedrosa, L. Codognoto, S. A. S. Machado, R. C. Rocha-Filho, L. A. Avaca. Electrochim. Acta. 2004, 49, 4021-4026.

[25] I. H. Tasdemir, M. A. Akay, N. Erk, E. Kilic. Electroanalysis. 2010, 22 (17-18), 2101-2109.

[26] S. E. W. Jones, R. G. Compton. Curr. Anal. Chem. 2008, 4, 170-176.

[27] G. R. Salazar-Banda, L. S. Andrade, P. A. P. Nascente, P. S. Pizani, R. C. Rocha-Filho, L. A. Avaca. Electrochim. Acta. 2006, 51, 4612-4619.

[28] S. C. B. Oliveira, V. C. Diculescu, G. Palleschi, D. Compagnone, A. M. Oliveira-Brett. Anal. Chim. Acta. 2007, 588, 283-291.

[29] G. R. Salazar-Banda, A. E. de Carvalho, L. S. Andrade, R. C. Rocha Filho, L. A. Avaca. J. Appl. Electrochem. 2010, 40, 1817-1827.

[30] D. T. Burns, K. Danzer, A. Townshend. Pure Appl. Chem. 2002, 74, 2201-2205.

[31] S. C. B. Oliveira and A. M. Oliveira-Brett. Electrochim. Acta. 2010, 55, 4599-4605.

[32] R. Greef, R. Peat, L. M. Pletcher, J. Robison, in: T. J. Kemp (Ed.), Instrumental Methods in Electrochemistry, Ellis Horwood, Chicherster, 1985, pp. 185-189.

[33] A. S. Lourenço, F. A. C. Sanches, R. R. Magalhães, D. J. E. Costa, W. F. Ribeiro, K. M. Bichinho, G. R. Salazar-Banda, M. C. U. Araújo. Talanta. 2014, 119, 509-516. 
[34] T. A. Silva, G. F. Pereira, O. Fatibello-Filho, K. I. B. Eguiluz, G. R. Salazar-Banda. Diamond Relat. Mater. 2015, 58, 103109.

[35] C. M. A. Brett, A. M. Oliveira-Brett, Electrochemistry: Principles, Methods and Applications Oxford University Press, Oxford, UK, 1993.

[36] F. Scholz, Electroanalytical Methods, Springer, New York, 2005.

[37] E. T. Smith. Anal. Chim. Acta. 2006, 572, 259-264.

[38] I. C. Lopes, P. V. F. Santos, V. C. Diculescu, F. M. P. Peixoto, M. C. U. Araújo, A. A. Tanaka, A. M. Oliveira-Brett. Analyst. 2012, 137, 1904-1912.

[39] T. A. Enache and A. M. Oliveira-Brett. Electroanalysis. 2011, 23, 1337-1344.

[40] M. Lovric, S. Kmorsky-Lovric. J. Electroanal. Chem. 1988, 248, 239-253.

[41] M. Lovric, S. Kmorsky-Lovric, R. W. Murray. Electrochim. Acta. 1988, 33, 739-744.

[42] J. Mocak, A. M. Bond, S. Mitchell, G. Scollary. Pure Appl. Chem. 1997, 69, 297-328.

[43] S. Suresh, Om. Kumar, P. Kolhe, V. K. Rao, K. Sekhar. Defence Sci. J. 2007, 57, 839-844.

[44] S. Suresh, A. K. Gupta, V. K. Rao, Om. Kumar and R. Vijayaraghavan. Talanta. 2010, 81, 703-708.
[45] S. Suresh, M. Gupta, G. A. Kumar, V. K. Rao, Om Kumara, P. Ghosal. Analyst. 2012, 137, 4086-4092.

[46] R. Stine, M. V. Pishko, C. L. Schengrund. Anal. Chem. 2005, 77, 2882-2888.

[47] G. P. Anderson, N. L. Nerurkar. J. Immunol. Methods. 2002, 271, 17-24.

[48] R. Kirby, E. J. Cho, B. Gehrke, T. Bayer, Y. S. Park, D. P. Neikirk, J. T. McDevitt, A. D. Ellington. Anal. Chem. 2004, 76, 4066-4075.

[49] E. A. Garber, R. M. Eppley, M. E. Stack, M. A. McLaughlin, D. L. Park. J. Food Prot. 2005, 68, 1294-1301.

[50] G. D. Griffiths, H. Newman, D. J. Gee. J. Forensic Sci. Soc. 1986, 26, 349-358.

[51] M. Ghosh, B. K. Bachhawat. Biochem. J. 1979, 183, 185-188.

[52] R. H. Shyu, H. F. Shyu, H. W. Liu, S. S. Tang. Toxicon. 2002, 40, 255-258.

[53] E. Duriez, F. Fenaille, J. C. Tabet, P. Lamourette, D. Hilaire, F. Becher, E. Ezan. J. Proteome. Res. 2008, 7, 4154-4163.

[54] N. Koja, T. Shibata, K. Mochida. Toxicon. 1980, 18, 611-618.

Received: February 21, 2017 Accepted: April 16, 2017

Published online on April 27, 2017 